three months. If publication can be continued, how ever, this chronicle is probably more valuable to the botanical world under present conditions than even in normal times.

\section{Rapid Glass-house Repair}

THE problem of repairing small holes in glasshouses both rapidly and economically has confronted many growers since the outbreak of war. After a thorough investigation of the matter, the Cheshunt Experimental and Research Station recommends the use of Bostik B. glazing compound, manufactured by the B. B. Chemical Co., Ltd., Ulverscroft Works, Leicester. The glass must be clean and perfectly dry. An extending nozzle is fitted to the Bostik tube, by means of which a thick flat continuous bead of the compound is delivered. This is allowed to dry for five or six minutes. The piece of glass which is to serve as a patch is then pressed lightly down on to the bead and a further film of Bostik applied around the outer edge of the patch to complete the seal. Glass substitutes can be used for patching instead of glass, and cracks can be satisfactorily sealed by a bead of the compound. All particulars are given in War-Time Notes No. 1, issued with the annual report of the Cheshunt Research Station for 1940.

\section{Health of Eire}

According to the report of the Department of Local Government of Eire for 1939-40, 1939, as in all parts of the world from which statistics are available, was a record year in Eire owing to the low prevalence and fatality of acute infectious diseases. There were only 2,779 notifications of scarlet fever with 43 deaths in 1939 , both figures being much the lowest on record. There were 2,097 cases of diphtheria with 245 deaths which accounted for nearly two thirds of all deaths from endemic infections. The fatality rate of diphtheria, as in all parts of the world, unlike that of measles, whooping-cough, and scarlet fever, showed no tendency to fall. There was an apparent increase in the mortality from tuberculosis, but this was probably accounted for by an improvement in notification.

\section{Vital Statistics of Switzerland}

RECENT statistics show that the decline in the birth-rate in Switzerland still continues. In.1939 it exceeded the death-rate by only 3.4 per thousand inhabitants as compared with $3 \cdot 6$ in $1938,4 \cdot 2$ in $1936,5 \cdot 6$ in $1930,6 \cdot 5$ in $1920,9.9$ in 1910 and 11.5 in 1903. The death-rate reached its lowest record in 1934 and in 1937 with $11 \cdot 3$, but rose to $11 \cdot 6$ in 1938 and 11.8 in 1939. Since 1871, with few exceptions, the marriage-rate has fluctuated between 6.8 and 7.9 , and the marriage age of single men has risen from $28 \cdot 5$ to $28 \cdot 9$, and of single women from $26 \cdot 1$ to $26 \cdot 7$.

\section{Mechanism of the Sun}

THE presidential address to the British Astronomical Association was delivered on October 29 by F. J. Sellers, and dealt with the sun. Mr. Sellers is director of the Section of the Association dealing with the sun, and has done a. considerable amount of research along certain lines. He has designed a very useful form of spectroscope and also a form of vibrating slit mechanism for the spectro-helioscope, and is a keen observer of solar phenomena. His address covered a very extensive field; here it is sufficient to say that the most up-to-date information on nuclear reactions in the interior of the sun, sunspots, the corona, chromospheric eruptions, etc., was discussed. The address is printed in full in the Journal of the British Astronomical Association (52, $1 ; 1941$ ).

\section{The Night Sky in February}

The moon is full on February $1 \mathrm{dd} .9 \mathrm{~h} .12 \mathrm{~m}$. and new on February 15d. 10h. 2m. U.T. Lunar conjunctions with the planets occur on the following dates: Venus on February 14d. 0h., Venus $5^{\circ} \mathrm{N}$.; Mars on February 22d. 1h., Mars $6^{\circ} \mathrm{N}$. ; Saturn on February 22d. 3h., Saturn $3^{\circ} \mathrm{N}$.; Jupiter on February $23 \mathrm{~d}$. $19 \mathrm{~h}$., Jupiter $5^{\circ} \mathrm{N}$. Mercury is an evening star until February 8, then a morning star. Venus is a morning star, and Mars, Jupiter and Saturn are evening stars. On February 24d. 2h. Mars is in con. junction with Saturn, Mars being $3 \cdot 5^{\circ} \mathrm{N}$. Mars, Jupiter and Saturn are still well placed for observation during the month. The planet Uranus, seen as a 6th magnitude star, is in the western part of Taurus and about $5^{\circ}$ south of the Pleiades. In the latitude of London the day lengthens by about $1 \frac{3}{4}$ hours during the month.

\section{Announcements}

Dr. Selig HeCHT, professor of biophysics at Columbia University, has been awarded the Frederic Ives Medal of the Optical Society of America for "distinguished work in the field of optics".

The Pan-American League for the Control of Cancer will meet this year at Buenos Aires under the presidency of Prof. H. Angel Roffo.

THE International Commission on Continental and Oceanic Structure of the International Union of Geodesy and Geophysics (chairman, Dr. R. M. Field) has found means to continue in operation the Scoresbysund seismological station, originally run in connexion with Danish stations. Funds were granted by the American Philosophical Society of Philadelphia, which will supply paper and other photographic materials for another year of operation. The supplies have been shipped.

THE Rugby Branch of the Association of Scientific Workers is conducting a series of lectures and meetings, held on Thursdays, on the general theme, "The Coming Post-War World". Among the speakers are Prof. V. H. Mottram on the social implications of dietetics, Capt. J. Langdon Davies on scientific invention at the service of the community, and Prof. A. St. G. Huggett on the social basis of physical and psychological health. Particulars can be obtained from the honorary secretary; J. B. Laurie, Upper Rainsbrook, Ashlawn Road, Rugby.

THE Clough Memorial Research Fund was instituted in 1935 for the purpose of encouraging geological research in Scotland and the North of England. The North of England is defined as comprising the counties of Northumberland, Cumberland, Durham, Westmorland and Yorkshire. Under the terms of administration of the fund a sum of approximately $£ 30$ is available annually. Applications for grants are invited for the period April 1, 1942-March 31, 1943, and should be made to the Secretary, Clough Research Fund Committee, Edinburgh Geological Society, Synod Hall, Castle Terrace, Edinburgh, not later than March 1. 